\title{
Temporal and Spatial Differences in Cell Wall Expansion during Bud and Mycelium Formation in Candida albicans
}

\author{
By MARGARET STAEBELL AND DAVID R. SOLL* \\ Department of Biology, University of Iowa, Iowa City, Iowa 52242, USA
}

(Received 10 October 1984)

\begin{abstract}
The infectious yeast Candida albicans is capable of growing in either a budding or mycelium form, depending upon the $\mathrm{pH}$ of the supporting medium. By monitoring the position of polylysine-coated beads firmly attached to the wall of growing cells, the zones of expansion for the surface of the cell wall have been mapped for the alternative growth forms. Both spatial and temporal differences are demonstrated to exist. During roughly the first two-thirds of bud growth, a very small, highly active apical zone accounts for roughly $70 \%$ of surface expansion. The remaining $30 \%$ is due to general expansion. When a bud reaches approximately two-thirds of its final surface area, the apical zone shuts down, and subsequent expansion is completed by the general mechanism. During mycelial growth, at least $90 \%$ of expansion is due to a small, highly active apical growth zone, and less than $10 \%$ is due to the general mechanism. In contrast to budding cells, the apical zone of the growing mycelium never shuts down as long as growth continues in the mycelial form. These distinct temporal and spatial differences in expansion are considered in terms of the regulation of alternative phenotypes in Candida.
\end{abstract}

\section{INTRODUCTION}

The dimorphic yeast Candida albicans is capable of growing in either a budding or mycelial form, depending upon the $\mathrm{pH}$ and temperature of the supporting medium (Buffo et al., 1984; Soll, 1984; Mitchell \& Soll, 1979a), as well as the growth history of the cells (Soll, 1984). Although the phenotypes of the two forms are distinct, few, if any, qualitative differences have been demonstrated, especially when the alternative forms are grown at the same temperature and in the same nutrient medium, the single factor determining phenotype, in this case, being pH (Soll, 1984; Brummel \& Soll, 1982; Soll et al., 1981b). These results have led to the suggestion that temporal and spatial, rather than qualitative, differences in subcellular events related to the cell cycle may be involved in the expression of alternative phenotypes (Soll, 1984; Soll \& Mitchell, 1983; Mitchell \& Soll, 1979b).

The most obvious difference between the alternative phenotypes is the shape of the growing daughter cell (Herman \& Soll, 1984). In the budding form, an evagination which appears on the mother cell expands into a mature daughter cell, ellipsoidal in shape. The daughter cell stops growing when it attains a particular volume (Herman \& Soll, 1984). In the mycelial form, an evagination which appears on the mother cell expands into an elongated tube, far narrower than the bud (Soll et al., 1981 b; Herman \& Soll, 1984). In contrast to a bud, the tube grows uninterruptedly as an elongated mycelium or hypha (Soll et al., 1981 b; Wain et al., 1976; Gow \& Gooday, 1982). These differences in shape as well as growth continuity must somehow translate into spatial and temporal differences in cell wall deposition. We have therefore examined the spatial and temporal dynamics of cell wall expansion during bud and mycelium formation under the regime of $\mathrm{pH}$-regulated dimorphism by continuously video-recording the position of polylysine-coated beads bound tightly to the surfaces of immature cells growing in perfusion chambers (Soll \& Herman, 1983; Herman \& Soll, 1984). The results clearly demonstrate at least two distinct mechanisms of surface expansion: (1) an extremely small, highly active apical zone 
of expansion and (2) a general mechanism of expansion. Dramatic differences in the temporal regulation of these mechanisms appear to be basic to the genesis of the alternative growth phenotypes of Candida.

\section{METHODS}

Stock culture conditions. Methods for maintaining stock cultures of strain 3153A of Candida albicans have been described in detail in several previous reports (Soll \& Bedell, 1978; Soll et al., 1978; Bedell et al., 1980). For experimental purposes, cells from an agar slant culture of a previously characterized clone were inoculated into $25 \mathrm{ml}$ defined medium (Lee et al., 1975) supplemented with $70 \mu \mathrm{g}$ arginine per $\mathrm{ml}$ in a $125 \mathrm{ml}$ Erlenmeyer flask and rotated in a New Brunswick rotatory shaker at 200 r.p.m. at $25^{\circ} \mathrm{C}$. Cells were grown serially through two rounds of growth, including roughly 10 generations, before being used in an experiment. Cells were not mass-cultured for more than one week in order to ensure genotypic and phenotypic homogeneity.

Induction of synchronous bud or mycelium formation. Cells were grown in defined nutrient medium at $25^{\circ} \mathrm{C}$ to stationary phase where they accumulated as unbudded singlets in the Gl phase of the cell cycle (Soll, 1984; Soll \& Bedell, 1978). After 24 to $36 \mathrm{~h}$ in stationary phase, cells were pelleted and resuspended in $15 \mathrm{ml}$ fresh nutrient medium in a $125 \mathrm{ml}$ Erlenmeyer flask to a final concentration of $1.5 \times 10^{7}$ spheres per ml. Cells were then rotated at 200 r.p.m. at $37^{\circ} \mathrm{C}$. When the $\mathrm{pH}$ of the nutrient medium was $4 \cdot 5$, cells evaginated synchronously after an average lag period of $135 \mathrm{~min}$ and each evagination expanded into an ellipsoidal bud; when the $\mathrm{pH}$ of the nutrient medium was $6 \cdot 7$, cells also evaginated synchronously after an average lag period of 135 min but each evagination then elongated as a mycelium. Details of the regulation of phenotype by this method of 'pH-regulated dimorphism' have been presented in previous reports (Buffo et al., 1984; Brummel \& Soll, 1982; Soll et al., 1981 b).

Treatment of beads for adhesion studies. Polystyrene beads (Polysciences, Warrington, Penn., USA) with diameters of $0.45 \mu \mathrm{m}, 0.5 \mu \mathrm{m}$ or $0.6 \mu \mathrm{m}$ were suspended in a $0.1 \%$ solution of polylysine, vortexed, and then lightly sonicated. Beads were incubated for $1 \mathrm{~min}$, pelleted, washed once with $1 \mathrm{ml}$ double-distilled water, vortexed, and again lightly sonicated. Beads were pelleted and the above treatment repeated. Beads were always coated with polylysine $2 \mathrm{~h}$ before an adhesion experiment.

Marking cells with polylysine-coated beads. To mark either growing buds or mycelia with beads, $0.7 \mathrm{ml}$ of a suspension of evaginated cells ( $135 \mathrm{~min}$ after release from stationary phase; see section above on induction of bud or mycelium formation) was mixed with $0.3 \mathrm{ml}$ pretreated beads, vortexed, and lightly sonicated. This mixture was then incubated for $1 \mathrm{~min}$, pelleted, and resuspended in $1 \mathrm{ml}$ prewarmed $\left(37^{\circ} \mathrm{C}\right)$ nutrient medium. This final suspension of cells with adhering beads was then used to inoculate the perfusion chamber. Scanning electron micrographs of beads attached to buds are presented in Fig. $1(a, b)$ and of beads attached to mycelia in Fig. $1(c, d)$.

Monitoring bead position during growth in a perfusion chamber. Both the method for preparing a perfusion chamber and the methods for inoculating cells into the chamber and monitoring growth by video analysis have been described in detail in two previous reports (Soll \& Herman, 1983; Herman \& Soll, 1984). In brief, a droplet of cells treated with polystyrene beads was placed on one side of the inner wall of a Sykes-Moore chamber (Bellco Glass, Vineland, NJ, USA) which had been coated with polylysine. The opposing chamber wall was immediately set in place and the chamber perfused with fresh medium at $37^{\circ} \mathrm{C}, \mathrm{pH} 4.5$ for bud growth or $\mathrm{pH} 6.7$ for mycelium growth. The temperature of the chamber was regulated by an air curtain incubator and prewarmed medium. Temperature was monitored continuously in the chamber by a digital thermometer with a microprobe inserted through an orifice on the chamber edge. Medium was prewarmed in a water bath incubator, aerated continuously, and pumped through the chamber at $0.5 \mathrm{ml} \mathrm{min}^{-1}$ by means of a peristaltic pump attached to the outflow tube.

The chamber was mounted in a trinocular Leitz phase contrast microscope equipped with a video camera and a long-range condenser lens. Video recordings of the cultures were made through an RCA camera attached to a Panasonic video cassette recorder (Soll \& Herman, 1983; Herman \& Soll, 1984).

Measurements of bead position. Video recordings of cells and adhering beads at $10 \mathrm{~min}$ intervals were projected as still frames on the screen of a video monitor. The mother and daughter cell periphery and the bead periphery were copied from the monitor screen onto a transparent plastic overlay. Morphometric measurements were then made with a digitizer (Laboratory Computer Systems, Cambridge, Mass., USA) connected to an IBM personal computer programmed for data storage and rapid calculation of a number of morphometric parameters. The following parameters, not all of which were used in the present study, were measured for each budding cell at each time point: (1) mother cell length, (2) mother cell width, (3) bud length, (4) bud width, (5) the circumferential distance from the centre of the mother cell-bud junction to the point of bead attachment $(l),(6)$ the circumferential distance from the point of bead attachment to the apex of the bud $(m)$, and $(7)$ the circumferential distance from the centre of the mother cell-bud junction to the apex of the bud $(n)$. The following parameters, not all of which were used in the present study, were measured for each mycelium-forming cell at each time point: (1) mother cell length, (2) mother cell width, (3) mycelial length, (4) mycelial width, (5) the circumferential distance from the junction of mother cell and mycelium to the point of bead attachment $(l),(6)$ the circumferential distance from the point of bead attachment to the apex of the mycelium $(m)$, and (7) the circumferential distance from the junction of the mother cell and mycelium to the apex of the mycelium $(n)$. A diagram of a bud and mycelium with the parameters used in the present analysis $(I, m$ and $n)$ are presented in Fig. $2(a)$ and Fig. 2(b), respectively. 

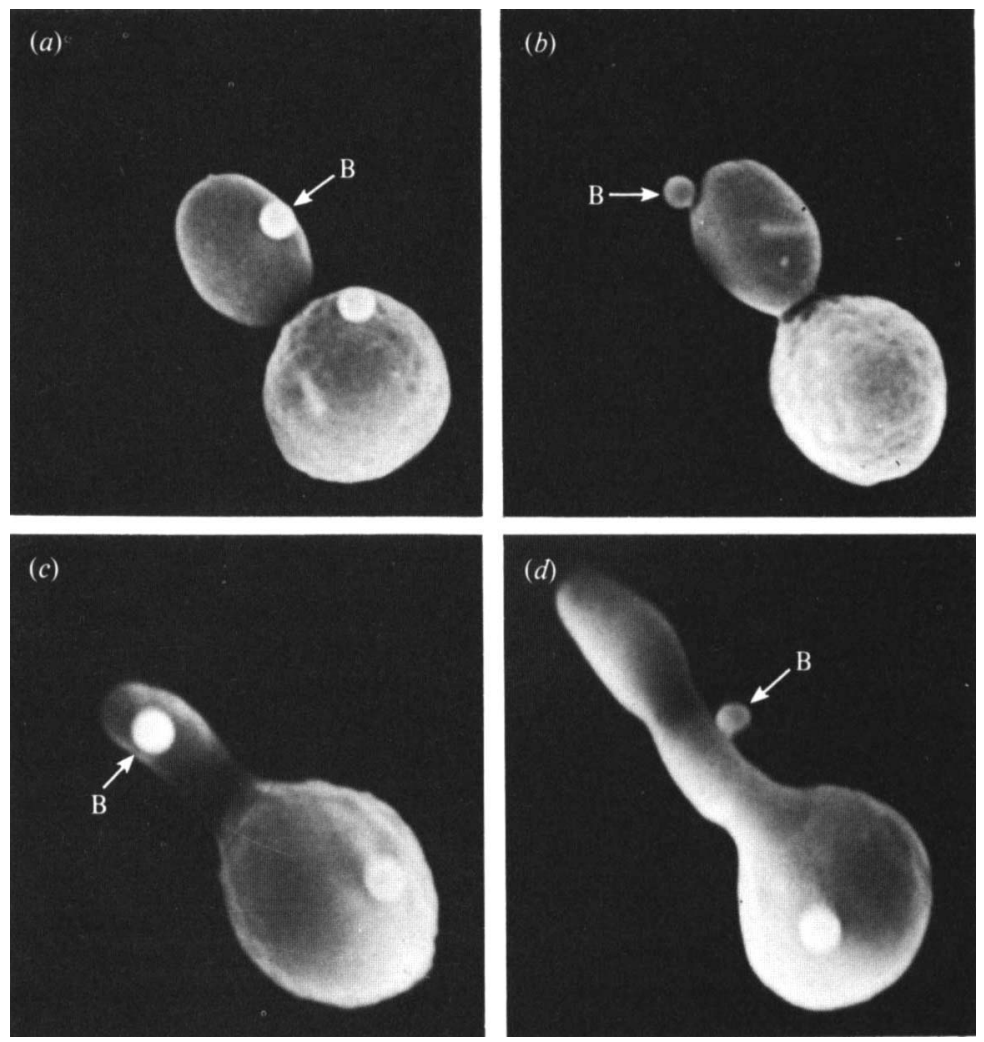

Fig. 1. Scanning electron micrographs of polylysine-coated beads (B) attached to buds $(a, b)$ or mycelia $(c, d)$ before inoculation into perfusion chambers. Magnification is approx. $5000 \times$.

\section{RESULTS}

\section{Bud and mycelium formation}

When cells enter stationary phase at $25^{\circ} \mathrm{C}$ under zinc-limiting conditions (Soll et al., 1981 a; Bedell \& Soll, 1979; Soll, 1985), they accumulate in G1 as unbudded singlets (Soll \& Bedell, 1978). These cells acquire pluripotency (Lee et al., 1975; Chaffin \& Sogin, 1976; Soll et al., 1981 a; Soll \& Bedell, 1978; Bedell \& Soll, 1979; Soll, 1984, 1985). When diluted into fresh medium at $37^{\circ} \mathrm{C}, \mathrm{pH} 4.5$, cells evaginate synchronously after an average lag period of $135 \mathrm{~min}$ (Soll et al., 1981 $a$; Bedell \& Soll, 1979; Soll, 1984, 1985). Each evagination then expands into an ellipsoidal bud (Bedell et al., 1980). After 200 min first the mother cell and then the original bud evaginates, and each evagination again expands into a mature bud (Herman \& Soll, 1984). Fig. $3(a-e)$ and Fig. 3( $f-j)$ present tracings of video recordings of mother cell and initial bud at time intervals in a perfusion chamber. Scanning electron micrographs of budding cells are presented in Fig. 1 $(a, b)$.

Alternatively, when cells which have entered stationary phase at $25^{\circ} \mathrm{C}$ are diluted into fresh medium at $37^{\circ} \mathrm{C}, \mathrm{pH} 6 \cdot 7$, they also evaginate synchronously after an average lag period of $135 \mathrm{~min}$ (Soll et al., 1981 $a$; Bedell \& Soll, 1979; Soll, 1985). However, in contrast to cells released into fresh medium at $\mathrm{pH} 4 \cdot 5$, each evagination then elongates into a germ tube, or incipient mycelium, and continues to grow as an elongating mycelium (Bedell et al., 1980; Buffoet al., 1984). Fig. $3(k-o)$ and Fig. $3(p-t)$ present tracings of mycelium outgrowth at time intervals in a perfusion chamber. Scanning electron micrographs of mycelium-forming cells are presented in Fig. $1(c, d)$.

Several morphogenetic differences exist between the diverging cell types which will be important in the following comparison of wall expansion and which therefore should be emphasized. First, a bud grows to roughly a maximum volume in a transient manner, then stops 


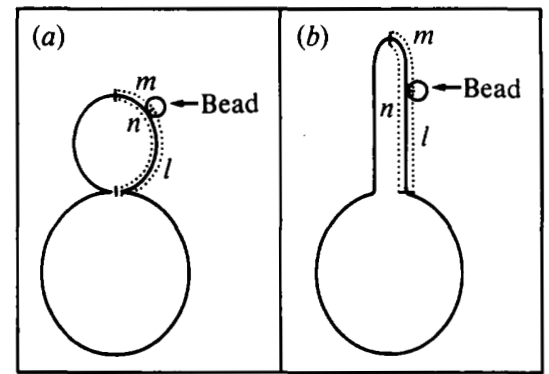

Fig. 2. Diagram of the parameters used to assess bead position on buds $(a)$ and mycelia $(b) . l$, The surface distance between junction and bead: $m$, the surface distance between bead and apex; $n$, the surface distance between junction and apex. Surface distance is represented as dotted lines.

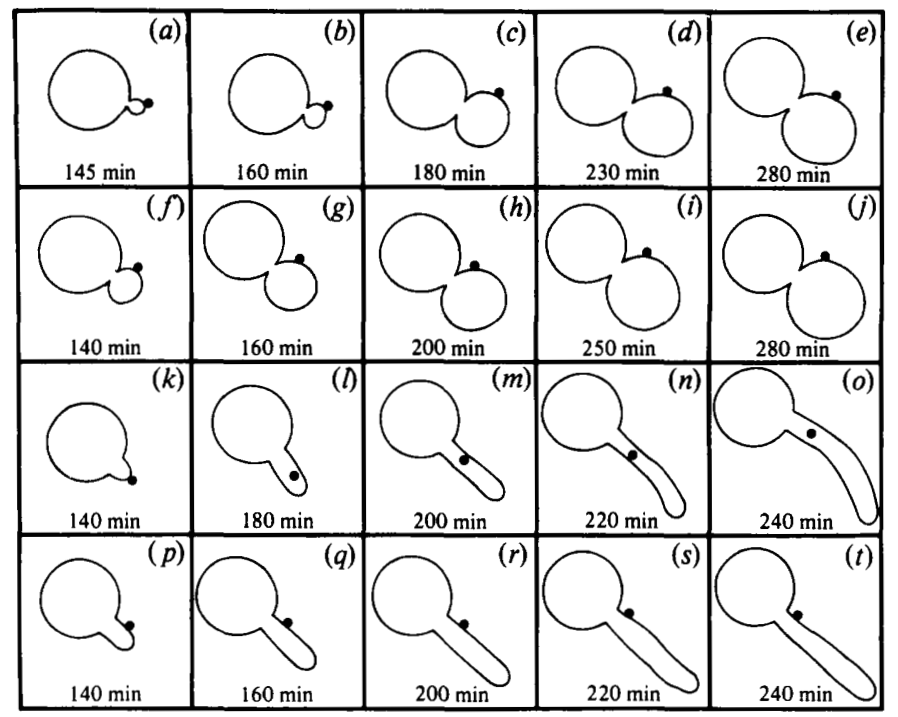

Fig. 3. Tracings of still frames from video recordings of two buds ( $a$ to $e$ and $f$ to $j$ ) and of two mycelia ( $k$ to $o$ and $p$ to $t$ ) with attached beads. Bead attachment occurred at $135 \mathrm{~min}$ after release from stationary phase at low $\mathrm{pH}(4.5)$ in the case of bud formation or high $\mathrm{pH}(6.7)$ in the case of mycelium formation. Subsequent times of still frames (in $\mathrm{min}$ ) are presented in the lower portion of each panel. Beads are drawn as filled circles. Beads on mother cells and secondary buds in the case of budding cells have been left out of the tracings.

growing as the mother cell and then the bud in turn evaginates (Herman \& Soll, 1984). In contrast, a mycelium elongates continuously (Soll et al., 1981 b; Wain et al., 1976; Gow \& Gooday, 1982) and, under the conditions of $\mathrm{pH}$-regulated dimorphism (Buffo et al., 1984), does not form secondary mycelia or buds. Second, the shape of the bud is round to ellipsoidal, whereas the shape of the mycelium is tubular (compare tracings in Fig. 3). Therefore, there is far more curvature in the bud wall. Third, there is no distinct constriction at the base of the tube, in contrast to a bud. Fourth, the septum forms invariably at the junction of mother and daughter cell during bud formation, but on average $2 \mu \mathrm{m}$ from the junction, along the tube, during mycelium formation (Soll \& Mitchell, 1983; Mitchell \& Soll, 1979b).

\section{Monitoring bead position during bud and mycelium formation}

Stationary phase cells were diluted into fresh medium at low $\mathrm{pH}$ to induce bud formation or high $\mathrm{pH}$ to induce mycelium formation. At $135 \mathrm{~min}$, the time at which roughly $50 \%$ of the cells had evaginated, an aliquot of cells was mixed with polylysine-coated beads, inoculated into a perfusion chamber, and immediately perfused with fresh medium at $37^{\circ} \mathrm{C}$, at the appropriate 
$\mathrm{pH}$ (see Methods for details). Time-lapse video recordings were made of individual cells and later analysed for both cell growth and bead position. Tracings of two representative budding cells with adhering beads are presented in Fig. 3(a-e) and Fig. 3(f-j). Tracings of two representative mycelium-forming cells are presented in Fig. $3(k-o)$ and Fig. $3(p-t)$.

Three parameters were monitored with time in order to assess bead position on a growing bud: $l$, the distance between the point of bead attachment and the centre of the mother cell-bud junction; $m$, the distance between the point of bead attachment and the apex of the bud; and $n$, the distance between the centre of the mother cell-bud junction and the apex of the bud (Fig. $2 a$ ). Similar parameters were monitored with time for growing mycelia: $l$, the distance between the point of bead attachment and the point of the mother cell-mycelium junction; $m$, the distance between the point of bead attachment and the apex of the mycelium; and $n$, the distance between the point of the mother cell-mycelium junction and the apex of the mycelium (Fig. $2 b$ ).

To assess the proportion of total wall expansion which occurred in the region between the mother-daughter cell junction and the point of bead attachment $(l)$ and that which occurred in the region between the point of bead attachment and the daughter cell apex $(m)$, the respective ratios $l / n$ and $m / n$ were used.

\section{Expansion during bud growth}

Two distinct patterns of bead behaviour on growing buds were distinguished. In the first pattern, designated pattern $\mathrm{A}, l / n$ decreased dramatically and $m / n$ increased dramatically during the initial portion of bud growth, and then remained relatively stable during the completion of bud growth; in the second pattern, designated pattern $\mathrm{B}, l / n$ and $m / n$ remained relatively stable throughout bud growth. Pattern A was observed almost exclusively in buds with semicircumferences $(n)$ at the time of bead attachment $(135 \mathrm{~min})$ which were less than $50 \%$ of the final semicircumference (at $300 \mathrm{~min}$ ). Pattern B was observed almost exclusively in buds with semicircumferences at the time of bead attachment $(135 \mathrm{~min})$ which were greater than $50 \%$ of the final semicircumference (at $300 \mathrm{~min}$ ).

Pattern A. In pattern A, the absolute distance between the bead and the mother cell-bud junction $(l)$ increased at a low but constant rate throughout the entire period of growth (see Fig. $4 a, c)$. In contrast, the distance between the bead and the apex of the bud $(m)$ first increased at a very rapid rate, then at a markedly reduced rate (Fig. $4 a, c$ ). A clear transition between the first phase, designated phase I, and the second phase, designated phase II, was evident. A decrease in the rate of total wall $(n)$ expansion also occurred at the transition between phase I and II in the majority of cells examined.

In Fig. $4(b, d)$ the proportions $l / n$ and $m / n$ are plotted as functions of growth time for the two representative cells. There was a dramatic initial decrease in $l / n$ and a dramatic initial increase in $m / n$. After the transition from phase I to phase II, the ratios became relatively stable. It should be noted that, for the two representative cells in Fig. 4, the beads were initially positioned close to the apex of the bud, but were far closer to the equator of the bud at the time of transition to phase II.

Pattern A was observed in 30 of 32 buds which exhibited a semicircumference at the time of bead attachment ( $135 \mathrm{~min}$ ) of less than $50 \%$ of the final semicircumference at $300 \mathrm{~min}$ (Tables 1 and 2). In contrast, pattern $A$ was observed in only 1 of 15 buds which exhibited a semicircumference at the time of bead attachment of more than $50 \%$ of the final semicircumference (Tables 1 and 2).

The rapid, initial increase in $m$ appeared to account for the major portion of surface expansion during phase I for the majority of cells exhibiting pattern A (e.g. Fig. 5a,c). In addition, it was clear that $l$ increased at a low but constant rate through phases I and II, and that the rate of $m$ expansion decreased to a level comparable to that of $l$ in phase II (Fig. 5a,c). These results suggest that during phase I, a very active apical zone and weaker general expansion account for total expansion, and that during phase II only general expansion is active. The transition point between phases I and II appears to represent the shut-down of the apical expansion zone. 

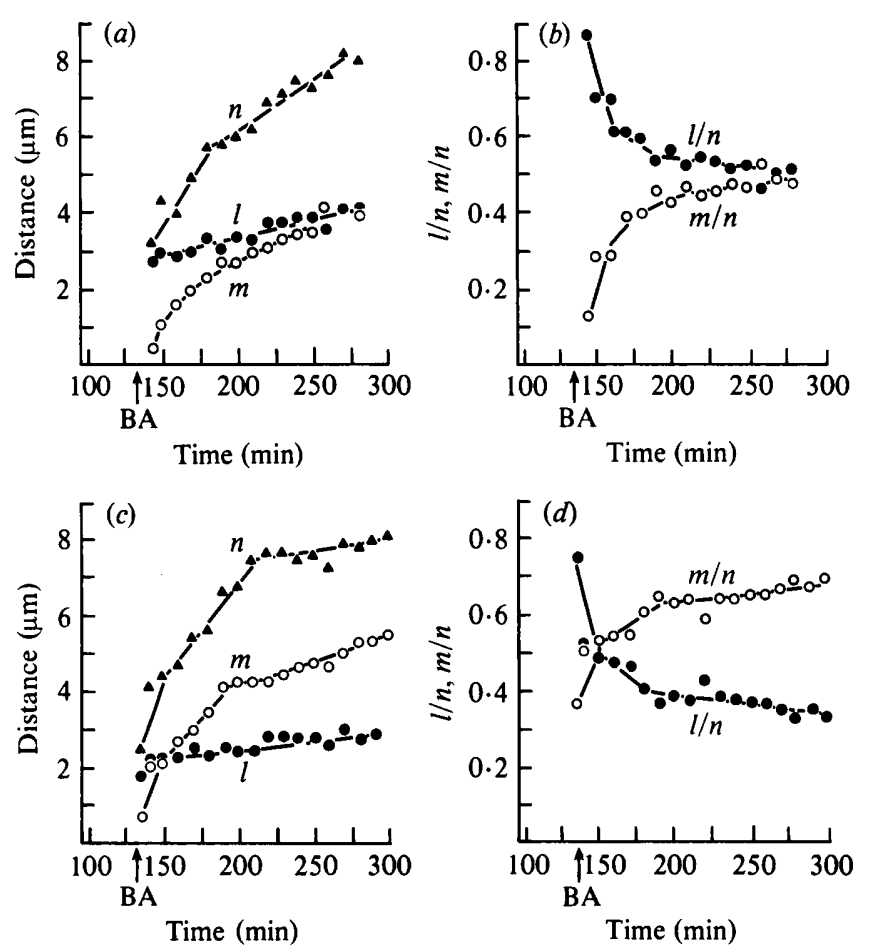

Fig. 4. Dynamics of bead position on two individual buds exhibiting pattern $A$. In $(a)$ and $(c)$, the parameters $l, m$ and $n$ are plotted as functions of time after bead adhesion (BA) for two independently monitored buds. In $(b)$ and $(d)$, the proportions $l / n$ and $m / n$ are plotted for the respective cells described in $(a)$ and $(c)$.

To examine this interpretation further, one can compare the observed value $l_{\mathrm{o}} / n_{\mathrm{I}}$ to the predicted value $l_{\mathrm{a}} / n_{\mathrm{l}}$, if expansion were completely apical, and to the predicted value $l_{\mathrm{g}} / n_{\mathrm{l}}$, if expansion were completely general. For these ratios, $l_{\mathrm{o}}$ is the observed value of $l$ at the end of phase $\mathrm{I}, l_{\mathrm{g}}$ is the predicted value at the end of phase $\mathrm{I}$ if expansion were solely general, $l_{\mathrm{a}}$ is the predicted value at the end of phase I if expansion were solely apical, and $n_{1}$ is the observed value of $n$ at the end of phase I. The predicted value for $l_{\mathrm{a}} / n_{\mathrm{I}}$ is simply $l_{145} / n_{\mathrm{l}}$, and the predicted value for $l_{\mathrm{g}} / n_{\mathrm{I}}$ is simply $l_{145} / n_{145}$. Values for $l_{\mathrm{o}} / n_{\mathrm{I}}, l_{\mathrm{a}} / n_{\mathrm{I}}$ and $l_{\mathrm{g}} / n_{\mathrm{I}}$ are listed in columns $(d),(e)$ and $(f)$, respectively, in Table 1 for 31 beaded buds exhibiting pattern $A$. It is clear that in every case the observed value fell between the value predicted for exclusively apical expansion and the value predicted for exclusively general expansion, indicating that both apical and general expansion components are involved in total expansion. For example, the bead on cell no. 2 in Table 1 is positioned at the apex of the bud at the time of bead adhesion $\left(l_{145} / n_{1}=1 \cdot 0\right)$. Purely apical expansion during phase I would have resulted in $l_{\mathrm{a}} / n_{\mathrm{I}}=0 \cdot 29$, and purely general expansion would have resulted in $l_{g} / n_{1}=1 \cdot 0$. The observed value was $0 \cdot 45$.

The percentage of total surface expansion (in the region $n$ ) during phase I due to general expansion was calculated from the formula $\left(l_{\mathrm{o}}-l_{145}\right) /\left(l_{\mathrm{g}}-l_{145}\right) \times 100$. The percentage of total surface expansion due to apical expansion was calculated by subtracting the percentage due to general expansion from 100 . Values of the apical and general proportions are presented in columns $(i)$ and $(j)$ in Table 1 for 31 beaded buds exhibiting pattern $A$. In 29 of 31 cases the apical component was greater than the general component during phase $I$. The mean value of the apical proportion was $72 \% \pm 18(\mathrm{SD})$, and the mean value of the general proportion was $28 \% \pm 18(\mathrm{SD})$.

Even though the population of 31 cells exhibiting pattern A (Table 1) increased their semicircumference by roughly $27 \%$ on average during phase II, there was very little change in the relative position of the bead. To demonstrate this point, the difference between $l / n$ at the end 


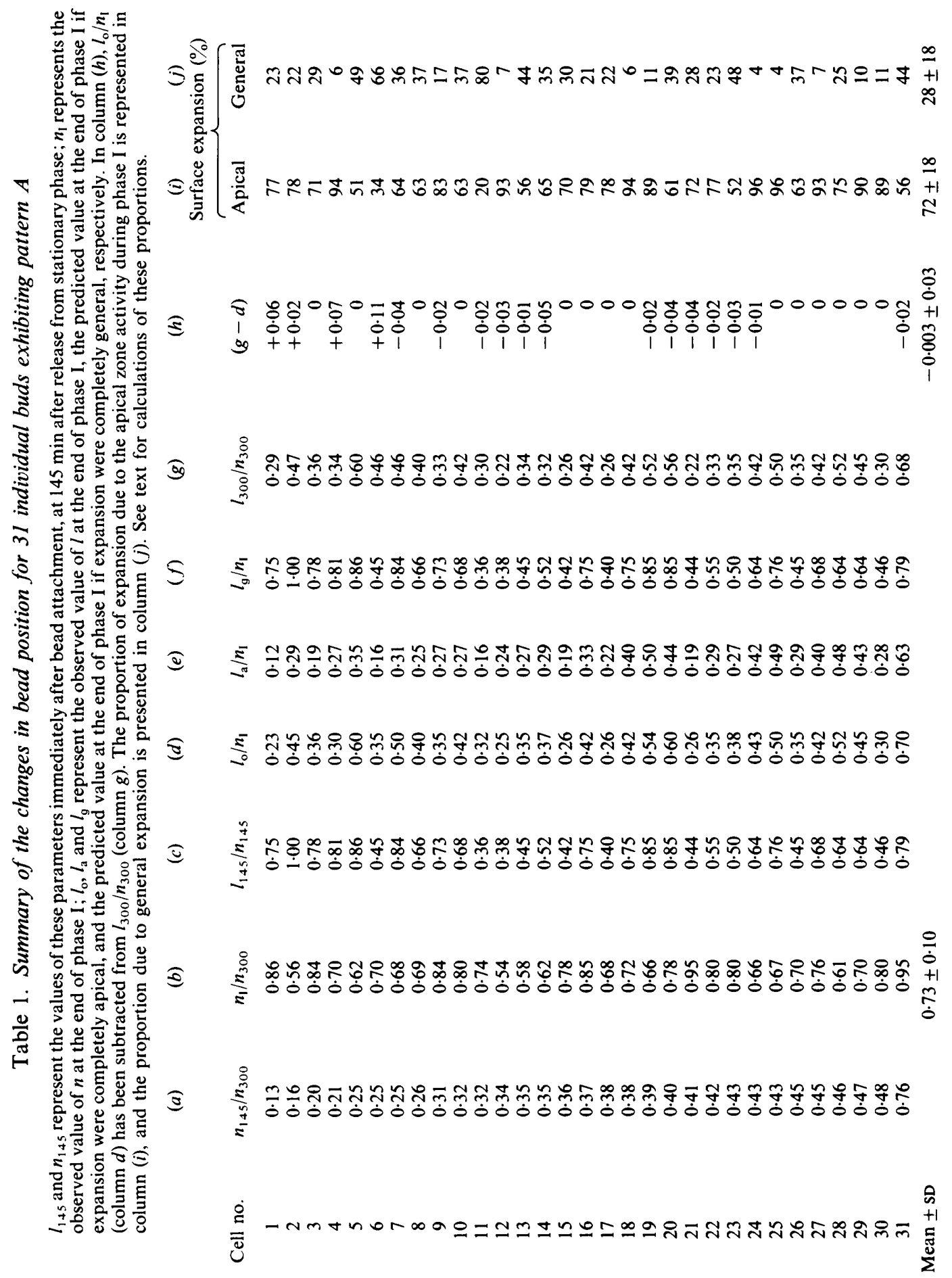



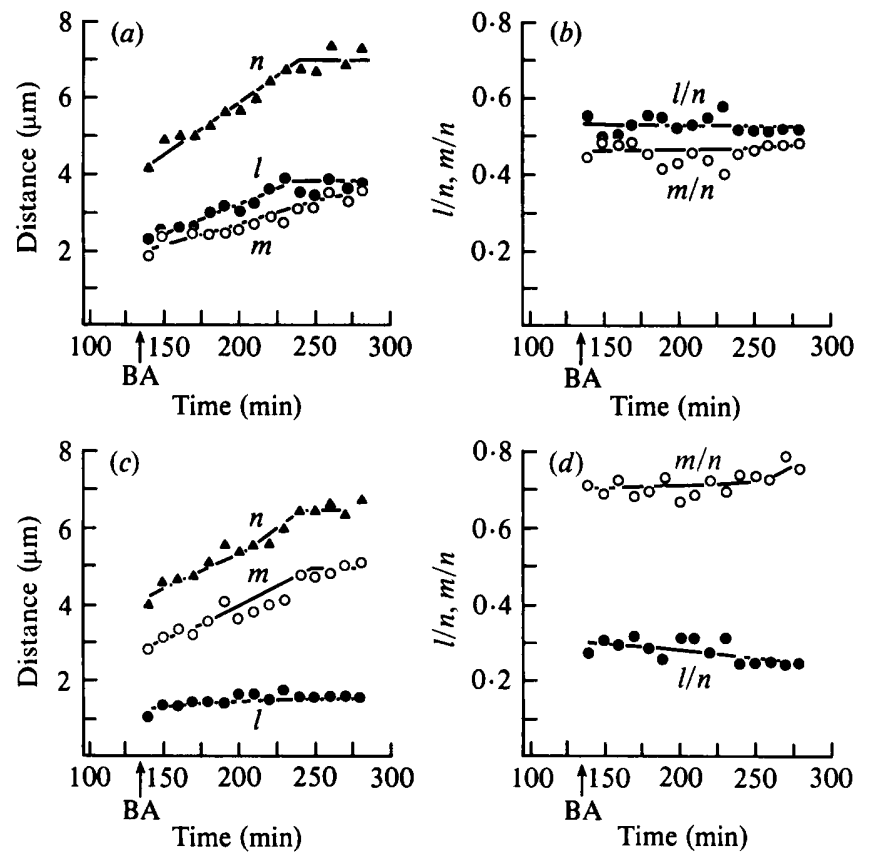

Fig. 5. Dynamics of bead position on two individual buds exhibiting pattern $\mathrm{B}$. In $(a)$ and $(c)$, the parameters $l, m$ and $n$ are plotted as functions of time after bead adhesion (BA) for two independently monitored buds. In $(b)$ and $(d)$, the proportions $/ / n$ and $m / n$ are plotted for the respective cells described in $(a)$ and $(c)$.

Table 2. Summary of the changes in bead position for 16 individual buds exhibiting pattern $B$

$l_{1+5}$ and $n_{300}$ represent the values immediately after bead attachment and at the end of the experiment, respectively. In column $(d), l_{145} / n_{145}$ (column $b$ ) has been subtracted from $l_{300} / n_{300}$ (column $c$ ).

$\begin{array}{ccccc}\text { Cell no. } & (a) & (b) & (c) & (d) \\ 1 & n_{1+5} / n_{300} & l_{145} / n_{145} & l_{300} / n_{300} & (c-b) \\ 2 & 0.35 & 0.36 & 0.32 & -0.04 \\ 3 & 0.48 & 0.24 & 0.24 & 0 \\ 4 & 0.51 & 0.77 & 0.72 & -0.05 \\ 5 & 0.51 & 0.28 & 0.35 & +0.07 \\ 6 & 0.52 & 0.65 & 0.62 & -0.03 \\ 7 & 0.56 & 0.24 & 0.23 & -0.01 \\ 8 & 0.57 & 0.44 & 0.35 & -0.09 \\ 9 & 0.57 & 0.20 & 0.20 & 0 \\ 10 & .0 .58 & 0.29 & 0.34 & +0.05 \\ 11 & 0.59 & 0.28 & 0.25 & -0.03 \\ 12 & 0.59 & 0.15 & 0.20 & +0.05 \\ 13 & 0.60 & 0.70 & 0.64 & -0.06 \\ 14 & 0.60 & 0.68 & 0.50 & -0.18 \\ 15 & 0.68 & 0.45 & 0.45 & 0 \\ 16 & 0.72 & 0.52 & 0.49 & -0.03 \\ \text { Mean } \pm \text { SD } & & 0.66 & 0.66 & 0 \\ & & & & -0.02 \pm 0.06\end{array}$

of phase I (column $d$, Table 1) and $l / n$ at the end of phase II (column $g$, Table 1) was calculated for each cell. The mean value for 31 cells was -0.003 . This supports the interpretation that expansion in the apical zone was negligible during phase II.

Pattern $B$. In Pattern B, $l$ and $m$ increased at low but constant rates throughout the entire period of analysis (see Fig. $5 a, c$ ). Unlike pattern A, no dramatic change in the rate of expansion of $m$, analogous to the transition point between phase I and phase II in pattern A, was evident. 
In addition, the proportions $l / n$ and $m / n$ remained relatively constant throughout the entire period of growth (see Fig. $5 b, d$ ). The initial rapid increase in $m / n$ and decrease in $l / n$ which occurred during phase $I$ in pattern A were absent.

Pattern B was observed in 14 of 15 cells with an initial semicircumference at the time of bead attachment (135 min) of more than $50 \%$ of the final semicircumference at $300 \mathrm{~min}$. Pattern B was observed in 2 of 30 cells with initial semicircumferences which were less than $50 \%$ of the final semicircumference at $300 \mathrm{~min}$. Relative bead position remained constant throughout the entire period of expansion in pattern B. This is demonstrated in column $(d)$ of Table 2 , in which the change in the proportion $l / n$ during the period of bud expansion is presented for 16 cells. The mean change was $-0.02 \pm 0.06(\mathrm{SD})$. The most reasonable explanation for pattern $B$ is simply that it represents general expansion. Because pattern B appeared predominantly in buds with initial semicircumferences (at $145 \mathrm{~min}$ ) which were greater than $50 \%$ of the final value measured at $260-300 \mathrm{~min}$, it is probable that these cells were treated with beads after they had entered phase II.

\section{Size of the apical expansion zone in budding cells}

Although the results summarized in Table 1 demonstrate that an apical zone of rapid wall expansion exists, they do not immediately suggest its size. If the apical zone were quite large, one would expect beads caught in the zone to remain apical during wall expansion. In this case, the proportion $l / n$ should be relatively constant during the initial rapid expansion period of small buds. In contrast, if the apical expansion zone were confined to a very small terminal region, then beads even at the apparent apex would exhibit a rapid decrease in the proportion $l / n$. To distinguish between these possibilities, we examined the behaviour of beads which bound initially very close to the apices of small buds. For the five cells examined (cell nos 2, 5, 7 , 19 and 20 in Table 1), the initial proportion $l / n$ ranged from 0.84 to 1.00 . In all cases, this proportion decreased rapidly through phase $\mathrm{I}$, and the proportion $m / n$ increased rapidly in a reciprocal fashion. In no case did we observe a retention of the bead in the apical region, leading to the conclusion that rapid apical expansion during phase $\mathrm{I}$ is restricted to a very small region at the tip.

\section{Wall expansion during mycelial growth}

A single pattern of bead behaviour was observed on growing mycelia. As mycelia elongated, distance $m$ increased at a constant rate, and accounted for the major portion of total mycelial wall expansion. In contrast, distance $l$ increased at an extremely low or negligible rate (Fig. $6 a, c)$ and, on average, accounted for less than $5 \%$ of the increase in $n$ between 135 and $300 \mathrm{~min}$. This pattern was true for beads attached close to the mother cell-mycelium junction (e.g. see cell nos 9 and 13 in Table 3) as well as for beads attached several $\mu \mathrm{m}$ from the junction (e.g. see cell nos 12 and 18 in Table 3). These results demonstrate that surface expansion of mycelia is predominantly terminal. In addition, beads which were nearly apical (e.g. see cell nos 12, 21 and 23 in Table 3) exhibited the same pattern, indicating that the expansion zone was limited to a very small region at the mycelial apex, as was the case for the terminal expansion zone of buds during pattern A.

Several differences between the mycelial pattern of expansion and the budding pattern of expansion should be pointed out. First, the apical zone of the bud shuts down after the bud has grown to roughly $70 \%$ of its final semicircumference, but the apical zone of the mycelium remains active as long as the mycelium continues to grow in the strict mycelial mode. Second, general expansion is far more active in buds than in mycelia. This is best demonstrated by comparing the average increase in $l$ during the period 135 to $300 \mathrm{~min}$. In mycelia, the mean increase of $l$ was $0.4 \mu \mathrm{m} \pm 0.5(\mathrm{SD})$, and in buds exhibiting pattern $A$ the mean increase of $l$ was $1.3 \mu \mathrm{m} \pm 0.4(\mathrm{SD})$. In addition, it should be noted that in mycelia, the largest increase in $l$ was usually transient, and when observed was restricted to cells which exhibited a transient increase in diameter. Elongate, narrow mycelia exhibited the smallest increases or no increase in $l$. 

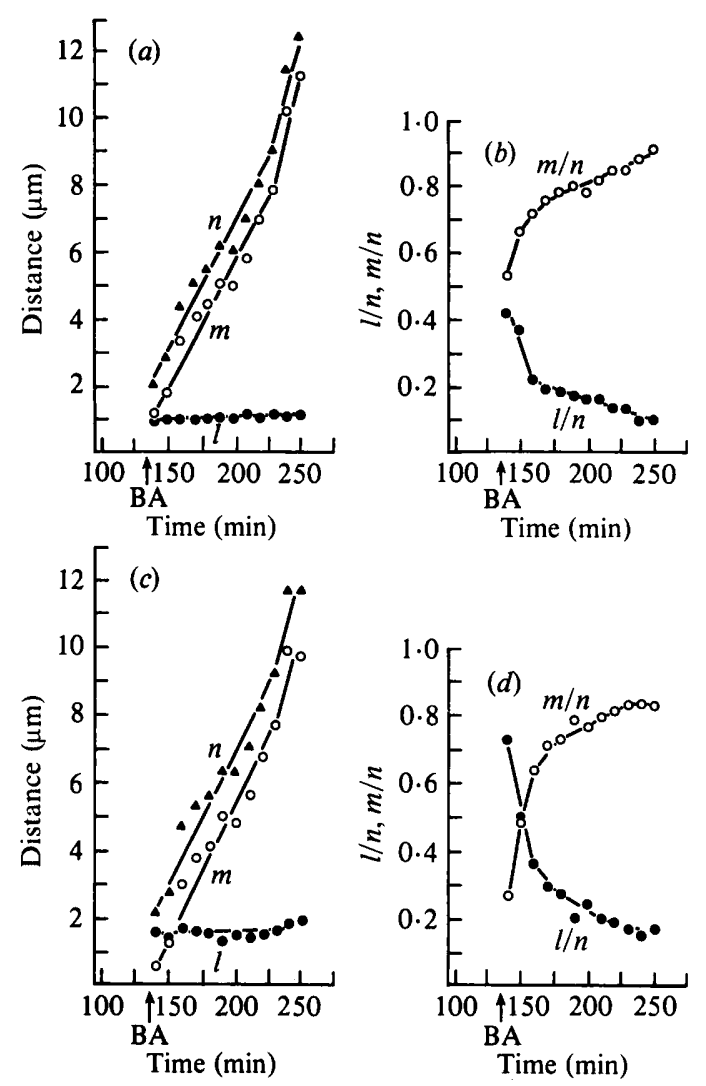

Fig. 6. Dynamics of bead position on two individual mycelia. In $(a)$ and $(c)$, the parameters $l, m$ and $n$ are plotted as functions of time after bead adhesion (BA) for two independently monitored mycelia. In $(b)$ and $(d)$, the proportions $l / n$ and $m / n$ are plotted for the respective cells described in $(a)$ and $(c)$.

\section{DISCUSSION}

For the present study, we have used a simple method for monitoring expansion of the cell wall surface. Polystyrene beads coated with polylysine were applied to cells at different points in their growth cycle, and bead position was monitored with time. The highly reproducible patterns of bead behaviour on buds and mycelia of different size demonstrate that there is no random change in bead position. This method provides a spatial and temporal account of wall expansion in a single cell. Unlike autoradiographic and fluorescent methods, cells do not have to be fixed at each time point, forcing the investigator to reconstruct temporal and spatial events from a set of individually fixed cells assumed to be in a particular growth sequence by virtue of time and size.

In a number of previous studies using autoradiographic and immunofluorescent staining methods, it has been demonstrated that growth of the cell wall of a yeast bud occurs primarily at the apex (Farkas, 1979; Tkacz \& Lampen, 1972; Biely et al., 1973; Farkas et al., 1974). Farkas et al. (1974) also found that when Saccharomyces cultures were pulse-labelled with radioactive mannose, very small, round buds exhibited a general pattern of incorporation, intermediatesized buds exhibited a predominantly apical pattern, and larger buds again exhibited a more general pattern. In the present analysis of bud surface expansion in Candida albicans, we have corroborated the last two components of this temporal programme of wall growth, but we have obtained no evidence of an initial general pattern of growth for very small buds (e.g. see cell nos $1,2,3$ and 4 in Table 1). It is possible that the general pattern of incorporation in very small buds observed by Farkas et al. (1974) was the result primarily of apical deposition of mannan for which the 5 min pulse time was sufficient for the amount of growth involved in generating the major portion of the small bud wall. Alternatively, the scheme of bud wall expansion may vary 
Table 3. Summary of the dynamics of bead position during mycelial growth for 23 individual cells

Subscripts 145 and 300 refer to the values of $l$ and $n$ immediately after bead adhesion and at the end of the experiment, respectively. The proportion of wall expansion due to general expansion (column $g$ ) was calculated by the formula $\left(l_{0}-l_{1+5}\right) /\left(l_{\mathrm{g}}-l_{1+5}\right) \times 100$, in which $l_{\mathrm{o}}$ equals $l_{300}$ and $l_{\mathrm{g}}$ equals $\left(l_{1+5} / n_{1+5}\right) \times n_{300}$.

\begin{tabular}{|c|c|c|c|c|c|c|c|}
\hline Cell no. & $\begin{array}{c}(a) \\
n_{1+5} \\
(\mu \mathrm{m})\end{array}$ & $\begin{array}{c}(b) \\
l_{1+5} / n_{1+5}\end{array}$ & $\begin{array}{c}(c) \\
n_{300} \\
(\mu \mathrm{m})\end{array}$ & $\begin{array}{c}(d) \\
l_{300} / n_{300}\end{array}$ & $\begin{array}{c}(e) \\
l_{300}-l_{145} \\
(\mu \mathrm{m})\end{array}$ & $\begin{array}{c}(f) \\
n_{300}-n_{145} \\
(\mu \mathrm{m})\end{array}$ & $\begin{array}{c}(g) \\
\text { General surface } \\
\text { expansion }(\%)\end{array}$ \\
\hline 1 & $1 \cdot 2$ & 0.82 & 9 & 0.13 & $0 \cdot 2$ & $7 \cdot 8$ & $3 \cdot 1$ \\
\hline 2 & $1 \cdot 2$ & 0.73 & 9 & 0.12 & $0 \cdot 2$ & $7 \cdot 8$ & $3 \cdot 5$ \\
\hline 3 & $1 \cdot 3$ & 0.73 & 14 & $0 \cdot 15$ & 1.5 & $12 \cdot 7$ & $15 \cdot 8$ \\
\hline 4 & $1 \cdot 5$ & 0.62 & 14 & 0.13 & $1 \cdot 1$ & $12 \cdot 5$ & $14 \cdot 0$ \\
\hline 5 & $2 \cdot 0$ & 0.98 & 13 & $0 \cdot 18$ & 0.4 & $11 \cdot 0$ & $3 \cdot 7$ \\
\hline 6 & $2 \cdot 1$ & 0.43 & 11 & $0 \cdot 10$ & 0.4 & $9 \cdot 0$ & $10 \cdot 4$ \\
\hline 7 & $2 \cdot 1$ & 0.44 & 12 & $0 \cdot 14$ & 0.2 & $10 \cdot 0$ & 4.7 \\
\hline 8 & $2 \cdot 1$ & 0.62 & 13 & $0 \cdot 13$ & $0 \cdot 3$ & $11 \cdot 0$ & $4 \cdot 4$ \\
\hline 9 & $2 \cdot 2$ & 0.27 & 13 & 0.07 & 0.3 & $11 \cdot 0$ & $13 \cdot 0$ \\
\hline 10 & $2 \cdot 2$ & 0.73 & 10 & $0 \cdot 16$ & 0.2 & 8.0 & $3 \cdot 4$ \\
\hline 11 & $2 \cdot 2$ & $0 \cdot 37$ & 12 & 0.08 & $0 \cdot 2$ & $10 \cdot 0$ & $5 \cdot 5$ \\
\hline 12 & $2 \cdot 5$ & 0.38 & 17 & $0 \cdot 10$ & 0.5 & 14.5 & 9.0 \\
\hline 13 & 3.6 & 0.91 & 8 & 0.39 & 0 & 4.5 & 0 \\
\hline 14 & $4 \cdot 0$ & 0.22 & 16 & 0.08 & 0.6 & $12 \cdot 0$ & $20 \cdot 0$ \\
\hline 15 & $4 \cdot 1$ & 0.25 & 21 & 0.09 & 0.6 & $17 \cdot 0$ & $14 \cdot 5$ \\
\hline 16 & $4 \cdot 1$ & $0 \cdot 16$ & 12 & 0.08 & 0.4 & 8.0 & $30 \cdot 0$ \\
\hline 17 & $4 \cdot 4$ & 0.94 & 14 & $0 \cdot 38$ & 0.5 & $9 \cdot 5$ & $5 \cdot 7$ \\
\hline 18 & $4 \cdot 6$ & 0.38 & 22 & $0 \cdot 12$ & 0.8 & $17 \cdot 5$ & $12 \cdot 0$ \\
\hline 19 & $5 \cdot 3$ & 0.91 & 13 & 0.40 & 0.2 & $7 \cdot 5$ & 13.0 \\
\hline 20 & $5 \cdot 3$ & 0.88 & 16 & 0.31 & 0.2 & $10 \cdot 7$ & $2 \cdot 2$ \\
\hline 21 & $5 \cdot 3$ & 0.19 & 13 & 0.11 & 0.2 & $7 \cdot 7$ & $15 \cdot 0$ \\
\hline 22 & $5 \cdot 4$ & 0.65 & 13 & $0 \cdot 35$ & 0.7 & $7 \cdot 5$ & $14 \cdot 0$ \\
\hline 23 & $6 \cdot 5$ & $0 \cdot 19$ & 17 & 0.08 & $0 \cdot 2$ & $10 \cdot 5$ & $10 \cdot 0$ \\
\hline Mean \pm SD & & & & & $0.4 \pm 0.3$ & $10 \cdot 3 \pm 3 \cdot 1$ & $9 \cdot 4 \pm 7$ \\
\hline
\end{tabular}

between Saccharomyces and Candida, or the deposition of mannan may not accurately reflect the zones of wall expansion at all stages of wall development. These alternatives are being tested.

Our results confirm a number of previous observations (Farkas, 1979; Tkacz \& Lampen, 1972; Biely et al., 1973; Farkas et al., 1974) which indicated that the major portion of wall expansion in a bud is apical. The capacity to quantify the apical and general components of surface expansion by the bead method has resulted in a rough proportion of 2 to 1 , respectively, during phase I. In addition, by analysing the behaviour of beads placed at the apex of a growing bud, we must conclude that the apical growth zone is localized in an extremely small terminal region. We have also confirmed the observation made by Farkas et al. (1974) that the apical growth zone shuts down before completion of the wall. Our results indicate that the apical zone shuts down when the semicircumference of the bud is roughly two-thirds of its final value. In addition, it is clear that general expansion continues uninterruptedly and at the same rate after the shut-down of the terminal component, accounting for the final one-third of expansion during phase II. At the end of phase II, general expansion shuts down (see Fig. 7 for a schematic diagram of the spatial and temporal events in bud wall expansion). Both the temporal and spatial differences in the two components of wall expansion indicate different mechanisms of wall growth, perhaps involving the deposition of different wall components. This latter possibility is now under intensive investigation.

The major objective of the present study was to compare the temporal and spatial dynamics of wall expansion between bud and mycelium formation. The differences observed are dramatic and appear to be basic in the differentiation of the alternative phenotypes. In both cases, expansion of the initial wall surface is due primarily to an extremely active, localized apical zone. Autoradiographic, fluorescent and serological analyses of hyphal elongation in Candida and a number of other fungi have also indicated that the major deposition of wall polysaccharide occurs predominantly at the hyphal apex (Bartnicki-Garcia \& Lippman, 1969; Galun et al., 


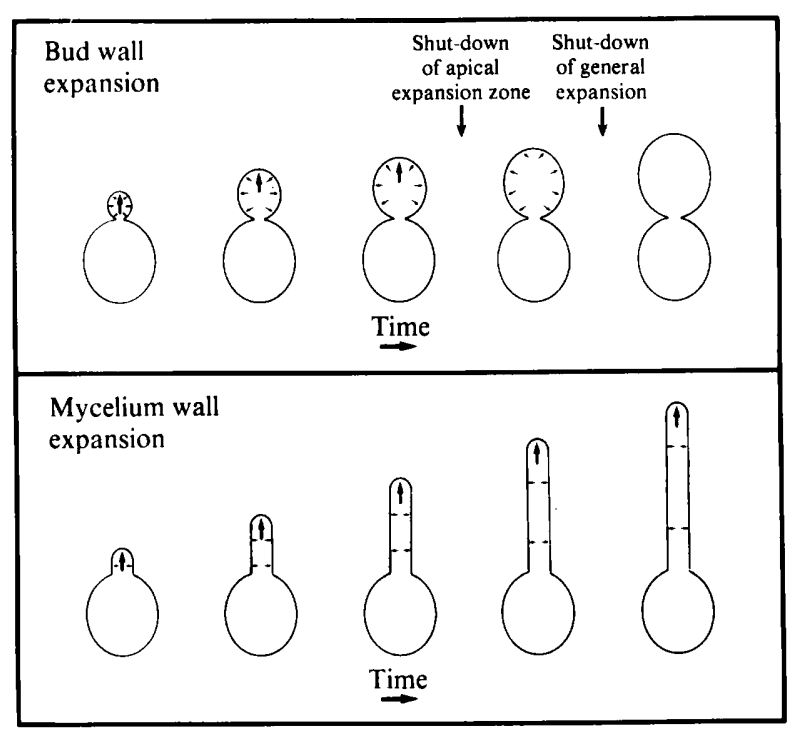

Fig. 7. Models of wall expansion during bud and mycelium formation in C. albicans under the regime of pH-regulated dimorphism. Large arrows in daughter cells represent the apical expansion zone; small arrows represent general expansion. Although we believe that general expansion is negligible in the growing mycelium under the most optimum conditions, a low level of general expansion is shown since it more accurately reflects the averaged data presented in this report.

1976; Gooday, 1971; Hunsley \& Kay, 1976; Marchant \& Smith, 1968). The present analysis of bead behaviour indicates that the rates of surface expansion due to the apical component in the bud during phase I and in the mycelium are roughly similar [e.g. compare initial plots for $m$ in Fig. 4(a,b) with plots for $m$ in Fig. 6(a,b)], leading to the suggestion that the zones in the alternative phenotypes may represent similar mechanisms of wall growth as well as the deposition of similar polysaccharides. In contrast, the general component of wall expansion differs significantly. During phase I of bud growth, the general component accounts, on average, for roughly $30 \%$ of wall expansion, but during mycelial growth it accounts for less than $10 \%$. In many cases, no general wall expansion was evident during mycelial elongation. In these latter cases, the mycelia remained narrow, adding support to the suggestion that general expansion is basic to sphere formation. Indeed, when we observed transient increases in mycelial diameter, we also observed transient general expansion (M. Staebell \& D. R. Soll, unpublished observation).

The most dramatic difference in surface expansion in buds and mycelia involves the temporal regulation of the apical component. When a bud expands to roughly two-thirds of its final surface area, the terminal component shuts down. In contrast, the terminal component of the mycelium remains maximally active as long as the mycelium continues growth strictly in the mycelial mode. During bud growth under the regime of pH-regulated dimorphism (Buffo et al., 1984; Brummel \& Soll, 1982; Soll et al., 1981 b), the mother cell appears to re-evaginate soon after the end of phase I (Herman \& Soll, 1984). Therefore, it may be more accurate to characterize the behaviour of the apical growth zone during the process of multiple bud formation as a change in location rather than as a complete shut-down, since the mother cell cytoplasm is contiguous first with the cytoplasm of the initial daughter bud and then with the cytoplasm of the secondary bud. During mycelium formation, the apical zone remains fixed and continuously active at the mycelium terminus. Although it does not shut down, or change location, it should be realized that the mycelium compartmentalizes. Therefore, the growth zone remains in the newest cell compartment, which is apical. One must therefore consider the possibility that the equivalent of an apical growth zone is continuously active in both budding cells and mycelia, and differs only in location. If this is in fact the case, it would be reasonable to 
suggest that the major difference between cells growing by consecutive buddings and cells growing by mycelial elongation is that the former relocates the apical growth zone and the latter does not.

In summary, we have identified two major differences in the expansion of the walls of buds and mycelia in C. albicans: (1) budding cells exhibit a significant level of general wall expansion while mycelia exhibit a relatively low level; (2) budding cells appear to shut down, or relocate, the apical growth zone after attaining a particular volume while mycelia maintain an active apical zone as long as they continue growth uninterruptedly in the mycelial mode. It should be noted that the single environmental variable which determines these differences is the $\mathrm{pH}$ of the supporting medium. Elucidating the mechanisms which underlie these spatial and temporal differences in wall expansion will be a necessary component of understanding the regulation of alternative phenotypes in Candida.

The authors are indebted to Michael Herman, Barbara Varnum, Beau Salisbury and Paula Jennings for their help in different portions of this project. This project was supported by grant no. PCM82-02380 from the National Science Foundation.

\section{REFERENCES}

BartNicki-Garcia, S. \& LipPMAN, E. (1969). Fungal morphogenesis: cell wall construction in Mucor rouxii. Science 165, 302-304.

Bedell, G. \& Soll, D. R. (1979). The effects of low concentration of zinc on the growth and dimorphism of Candida albicans: evidence for zinc-resistant and zinc-sensitive pathways for mycelium formation. Infection and Immunity 36, 348-354.

Bedell, G., Werth, A. \& Soll, D. R. (1980). The regulation of nuclear migration during synchronous bud formation in released stationary phase cultures of the yeast Candida albicans. Experimental Cell Research 127, 103-113.

Biely, P., Kovarik, J. \& Bauer, S. (1973). Cell wall formation in yeast, an electron microscopic autoradiographic study. Archives of Microbiology 94, 365371.

Brummel, M. \& Soll, D. R. (1982). The temporal regulation of protein synthesis during synchronous bud or mycelium formation in the dimorphic yeast Candida albicans. Developmental Biology 89, 211224.

Buffo, J., Herman, M. A. \& Soll, D. R. (1984). A characterization of $\mathrm{pH}$-regulated dimorphism in Candida albicans. Mycopathologia 85, 1-30.

Chaffin, W. L. \& Sogin, S. L. (1976). Germ tube formation from zonal rotor fractions of Candida albicans. Journal of Bacteriology 126, 771-776.

FARKAS, V. (1979). Biosynthesis of cell walls of fungi. Microbiological Reviews 43, 117-144.

Farkas, V., Kovarik, J., Kosinova, A. \& Bauer, S. (1974). Autoradiographic study of mannan incorporation into the growing cell walls of Saccharomyces cerevisiae. Journal of Bacteriology 117, 265-269.

Galun, M. A., Braun, A., FrensdorfF, A.\& Galun, E. (1976). Hyphal walls of isolated lichen fungi. Autoradiographic localization of precursor incorporation and binding of fluorescein-conjugated lectins. Archives of Microbiology 108, 9-16.

GoODAY, G. W. (1971). An autoradiographic study of hyphal growth of some fungi. Journal of General Microbiology 67, 125-133.

Gow, N. A. R. \& Gooday, G. W. (1982). Growth kinetics and morphology of colonies of the filamen- tous form of Candida albicans. Journal of General Microbiology 128, 2187-2194.

Herman, M. A. \& Soll, D. R. (1984). A comparison of volume growth during bud and mycelium formation in Candida albicans: a single cell analysis. Journal of General Microbiology 130, 2219-2228.

HunsLEY, D. \& KAY, D. (1976). Wall structure of the Neurospora hyphal apex: immunofluorescent localization of wall surface antigens. Journal of General Microbiology 95, 233-248.

LeE, K. L., BuCKLEY, H. R. \& CAMPbell, H. R. (1975). An amino acid liquid synthetic medium for development of mycelial and yeast forms of Candida albicans. Sabouraudia 13, 148-153.

Marchant, R. \& SMITh, D. G. (1968) A serological investigation of hyphal growth in Fusarium culmorum. Archives of Microbiology 63, 85-94.

Mitchell, L. \& Soll, D. R. (1979a). Commitment to germ tube or bud formation during release from stationary phase in Candida albicans. Experimental Cell Research 120, 167-179.

Mitchell, L. \& SolL, D. R. (1979b). Septation during synchronous mycelium and bud formation in released stationary phase cultures of Candida albicans. Experimental Mycology 3, 298-309.

Soll, D. R. (1984). The cell cycle and commitment to alternate cell fates in Candida albicans. In The Microbial Cell Cycle, pp. 143-162. Edited by P. Nurse \& E. Streiblova. Boca Raton, Florida: CRC Press.

Soll, D. R. (1985). The role of zinc in Candida dimorphism. In Current Topics in Medical Mycology, vol. 1. Edited by M. R. McGinnis. New York: Springer-Verlag (in the Press).

Soll, D. R. \& BEDELL, G. W. (1978). Bud formation and the inducibility of pseudo-mycelium outgrowth during release from stationary phase in Candida albicans. Journal of General Microbiology 108, 173180.

Soll, D. R. \& Herman, M. A. (1983). Growth and the inducibility of mycelium formation in Candida albicans: a single-cell analysis using a perfusion chamber. Journal of General Microbiology 129, 28092824. 
Soll, D. R. \& Mitchell, L. H. (1983). Filament ring formation in the dimorphic yeast Candida albicans. Journal of Cell Biology 96, 486-493.

Soll, D. R., Stasi, M. \& Bedell, G. W. (1978). The regulation of nuclear migration and division during pseudo-mycelium outgrowth in the dimorphic yeast Candida albicans. Experimental Cell Research 116, 207-215.

Soll, D. R., Bedell, G. W. \& BRummel, M. (1981a). Zinc and the regulation of growth and phenotype in the infectious yeast Candida albicans. Infection and Immunity 32, 1139-1147.

Soll, D. R., Bedell, G., Theil, J. \& Brummel, M. (1981b). The dependency of nuclear division on volume in the dimorphic yeast Candida albicans. Experimental Cell Research 133, 55-62.

TKaCZ, J. S. \& Lampen, J. O. (1972). Wall replication in Saccharomyces species: use of fluorescein-conjugated Concanavalin A to reveal the site of mannan insertion. Journal of General Microbiology 72, 243 247.

Wain, W. H., Price, M. F., Brayton, A. R. \& CaWson, R. A. (1976). Macromolecular synthesis during the cell cycles of yeast and hyphal phases of Candida albicans. Journal of General Microbiology 97 , $211-217$. 